\title{
Does Authenticity Matter in Corporate Social Responsibility Acts?
}

\author{
Sarah Alhouti, Catherine M. Johnson, and Betsy Bugg Holloway
}

\begin{abstract}
The study examines the role of authenticity in corporate social responsibility (CSR) acts through a qualitative and quantitative study. Three hundred and ninety qualitative commentaries are content analyzed to determine antecedents to CSR authenticity. The study finds that impact, perceived motive, reparation, and fit are vital in creating the perception of authentic CSR acts. Impact refers to the amount of resources allocated to assisting a cause and the company's impact on a cause. Perceived motive is the reason why CSR acts are being implemented. Reparation refers to the degree to which a CSR initiative is perceived to be an attempt to compensate for a misdeed. Fit is defined as the CSR initiatives alignment with the firm's offering, brand concept, or target market needs. The quantitative study proves that CSR authenticity mediates the influence on consumer outcome. The structural equation model also shows a significant effect of impact, reparation, and fit on CSR authenticity.
\end{abstract}

\footnotetext{
S. Alhouti $(\bowtie)$

Providence College, Providence, RI, USA

e-mail: salhouti@providence.edu

C.M. Johnson

University of Toledo, Toledo, $\mathrm{OH}$, USA

e-mail: smjohnson8@cba.ua.edu

B.B. Holloway

Samford University, Birmingham, AL, USA

e-mail: bbhollow@samford.edu
} 